\title{
Microstructural and tensile behavior of Fe-36\% Ni alloy after cryorolling and subsequent annealing
}

\author{
Jian-jun Zheng, Chang-sheng Li*, Shuai He, Ban Cai, Yan-lei Song
}

State Key Laboratory of Rolling and Automation, Northeastern University, Shenyang 110819,

\section{China}

\begin{abstract}
In this paper, the microstructure and mechanical properties of $\mathrm{Fe}-36 \% \mathrm{Ni}$ alloy after $90 \%$ reduction of cryorolling (CR) and subsequent annealing were investigated. The X-Ray diffraction (XRD) results indicated the existence of $\gamma \rightarrow \alpha^{\prime}$ phase transformation, and the measurement result of the $\alpha^{\prime}$ volume fraction was $15 \%$. Lath $\alpha^{\prime}$ with average thickness of $29.3 \mathrm{~nm}$ was then observed by transmission electron microscope (TEM). After 90\% reduction of CR, the ultimate strength (UTS) of the tested alloy was enhanced to $1100 \mathrm{MPa}$. This was mainly due to high density defects formation and $\alpha^{\prime}$ transformation during CR. After annealing at $823 \mathrm{~K}$ for $5 \mathrm{~min}$, TEM results revealed that a multimodal grain structure was produced, the UTS of the tested alloy was decreased to $830 \mathrm{MPa}$, total elongation (EL) was increased to $8 \%$. With the increasing of annealing time, the recrystallized grains were gradually coarsened and the volume fraction was increased. The increase of ductility was accompanied by the significantly decrease of strength. The cryorolled $\mathrm{Fe}-36 \% \mathrm{Ni}$ alloy was fully recrystallized after annealing at $823 \mathrm{~K}$ for $30 \mathrm{~min}$. The grain size distribution indicated that nearly $62 \%$ of the grains were less than $3 \mu \mathrm{m}$ and there were a few large grains more than $10 \mu \mathrm{m}$. The recrystallized sample exhibited a
\end{abstract}

\footnotetext{
* Corresponding Author: Chang-sheng LI, Professor; E-mail: lics@ ral.neu.edu.cn; Tel.: +86 24 83687749; fax: +862423906472.
} 
good mechanical property with a higher tensile strength of $550 \mathrm{MPa}$ and total EL of $36 \%$, which was probably due to the bimodal microstructure.

Keywords: Fe-36\%Ni alloy; Cryorolling; Microstructure; Stacking fault energy; Ultimate strength

\section{Introduction}

Fe-36\%Ni alloy is well known for its low thermal expansion coefficient over a wide temperature range [1]. Recently, $\mathrm{Fe}-36 \% \mathrm{Ni}$ alloy is more and more used as structural materials [2]. However, due to its relatively low strength, the application of $\mathrm{Fe}-36 \% \mathrm{Ni}$ alloy is always limited. Adding other alloy elements is an efficient way to enhance the mechanical properties of $\mathrm{Fe}-36 \% \mathrm{Ni}$ alloy. For instance, by adding $0.8 \%$ Be in Fe-40\% Ni alloy, the tensile strength and yield strength can be enhanced to 1100 $\mathrm{MPa}$ and $910 \mathrm{MPa}$ respectively, but the thermal expansion performance is destroyed [3]. Therefore, sever plastic deformation (SPD) is applied to strengthen $\mathrm{Fe}-36 \% \mathrm{Ni}$ alloy without sacrificing the low thermal expansion performance. The grain size of $\mathrm{Fe}-36 \% \mathrm{Ni}$ alloy can be refined to nano-scale via quasi-hydrostatic pressure, and the coefficient of thermal expansion is decreased due to the formation of ordered phase [4]. Ultra-fine grain $\mathrm{Fe}-36 \% \mathrm{Ni}$ alloy is also obtained by equal channel angular pressing (ECAP), the tensile stress is increased by a factor of two compared to Fe-36\% Ni alloy with conventional grain size [5].

Although the SPD methods mentioned above can significantly enhance the mechanical properties of $\mathrm{Fe}-36 \% \mathrm{Ni}$ alloy, it is difficult to realize in industrial production. Recently, cryorolling (CR) is getting more and more attention for it can 
induce severe strain and continuous produce large specimens [6, 7]. Wang et al. [8] investigated the microstructure and mechanical properties of pure $\mathrm{Cu}$ after $\mathrm{CR}$ and subsequent annealing. The results revealed that a bimodal grain size distribution was formed after annealing at $473 \mathrm{~K}$ for $3 \mathrm{~min}$. The tensile strength of the tested $\mathrm{Cu}$ was almost two times as large as that of the coarse-grained one, while the ductility was nearly not changed. A multimodal grain structure of commercial Ti was produced by $\mathrm{CR}$ and annealing. The tensile strength was enhanced to $945 \mathrm{MPa}$ and the total elongation was 23\% [9]. By CR and optimal subsequent annealing condition, pure $\mathrm{Al}$ was refined to sub-micron scale and exhibited good combination of high strength and good ductility [10]. CR can effectively suppress dynamic recovery, producing a high density of defects and refining grain size during subsequent annealing [11-13]. The aim of this paper is to improve the mechanical properties of $\mathrm{Fe}-36 \% \mathrm{Ni}$ alloy by $\mathrm{CR}$ and subsequent annealing treatment.

\section{Experimental procedure}

Samples were cut into dimensions of $80 \mathrm{~mm} \times 40 \mathrm{~mm} \times 5 \mathrm{~mm}$ and the $\mathrm{CR}$ was carried out on a $\phi 160 / 300 \times 300$ four high cold-rolling mill. During CR, samples were dipped in liquid nitrogen at least 10 min before and after each rolling pass, with a reduction of less than $15 \%$ per pass. The total rolling reduction was $90 \%$. After CR, the cryorolled specimens were annealed at $823 \mathrm{~K}$ for different times. Samples were cut in the plane containing the RD and ND for study of microstructure. The microstructures of the cryorolled and annealed samples were performed on Leica DMIRM optical microscope $(\mathrm{OM})$ and FEI Tecnai $\mathrm{G}^{2}$ F20 transmission electron 
microscope (TEM) respectively. For OM observation, the samples were etched in the $\mathrm{FeCl}_{3}$ supersaturated solution. For TEM investigation, the electro-polishing was carried out with 10 vol. $\% \mathrm{HClO}_{4}$ and 90 vol. $\% \mathrm{CH}_{3} \mathrm{COOH}$ solution at $263 \mathrm{~K}$ and a potential of $20 \mathrm{~V}$. The X-ray diffraction (XRD) measurements were carried out on with $\mathrm{Cu} \mathrm{K} \alpha$ radiation (wavelength $\mathrm{k}=0.154056 \mathrm{~nm}$ ). The scan speed of the XRD was $2^{\circ} /$ min and the scanned angle was between $40^{\circ}$ and $100^{\circ}$. The volume fraction of $\alpha$ was evaluated by Equ. (1) as following [14].

$$
\mathrm{V}_{\alpha^{\prime}}=\frac{(1 / \mathrm{n}) \sum_{\mathrm{j}=1}^{\mathrm{n}}\left(\mathrm{I}_{\alpha^{\prime}}^{\mathrm{j}} / \mathrm{R}_{\alpha^{\prime}}^{\mathrm{j}}\right)}{(1 / \mathrm{n}) \sum_{\mathrm{j}=1}^{\mathrm{n}}\left(\mathrm{I}_{\gamma}^{\mathrm{j}} / \mathrm{R}_{\gamma}^{\mathrm{j}}\right)+(1 / \mathrm{n}) \sum_{\mathrm{j}=1}^{\mathrm{n}}\left(\mathrm{I}_{\alpha^{\prime}}^{\mathrm{j}} / \mathrm{R}_{\alpha^{\prime}}^{\mathrm{j}}\right)}
$$

Where $\mathrm{n}$ was the number of peaks of the phase examined in calculation. The $\gamma$ peak (2 20 ), and $\alpha^{\prime}$ peaks (2 00 ) and (2 111 ) were selected. Where I was the integrated intensity of the reflecting plane, and $\mathrm{R}$ was the material scattering factor which was listed in Table 1.

The tensile test was performed at room temperature using a WDW300 materials testing machine at a constant crosshead speed of $1 \mathrm{~mm} / \mathrm{min}$. According to the ASTM Standard E-8/E8M-09 [15], the tensile specimens were prepared parallel to the rolling direction with a gauge length of $25 \mathrm{~mm}$, width of $6 \mathrm{~mm}$. To obtain the average engineering stress-strain curves for samples, at least three samples were tested.

\section{Results and discussion}

Microstructure of the initial material (hot rolled plate) with almost equiaxed grains and several annealing twins is shown in Fig. 1, and the average grain size is $18.2 \mu \mathrm{m}$.

The X-ray diffraction results of samples as-received and after $90 \%$ reduction of 
CR $(90 \% \mathrm{CR})$ are presented in Fig. 2. The results reveal that the original sample is fully austenitic containing $\gamma(111), \gamma(200), \quad \gamma(220)$ and $\gamma(311)$ peaks. Obviously, two new peaks of $\alpha^{\prime}(200)$ and $\alpha^{\prime}(211)$ can be detected, which shows that $\mathrm{CR}$ can induce the phase transformation of $\gamma \rightarrow \alpha$ in $\mathrm{Fe}-36 \% \mathrm{Ni}$ alloy. The volume fraction of $\alpha^{\prime}$ phase is $15 \%$ after $90 \%$ CR (Equ. (1)).

Fig. $3 \mathrm{a}$ is the TEM image indicating the microstructure of $\mathrm{Fe}-36 \% \mathrm{Ni}$ alloy after 90\% CR. The cryorolled sample exhibits typical lath $\alpha$ with average thickness of $29.3 \mathrm{~nm}$. The lath $\alpha^{\prime}$ can be clearly seen in the dark fielded image (Fig. 3b). The corresponding selected area electron diffraction pattern (SAED) along a $[011] / /[\overline{1} 11]$ zone axis (Fig. 3c) shows that the deformation induced $\alpha^{\prime}$ and austenite obey $\{111\}_{\gamma} / /\{110\}_{\alpha}$ and $\langle 110\rangle_{\gamma} / /\langle 11 \overline{1}\rangle_{\alpha}$ K-S orientation relationship.

As we know that the deformation mechanism of face centered cubic (FCC) metals is strongly dependent on the stacking fault energy (SFE) [16]. Fe-36\%Ni alloy is a typical intermediate $\operatorname{SFE}\left(\gamma=122 \mathrm{~mJ} \mathrm{~m}^{-2}\right.$ [17]) metal, only dislocation slip can be activated during room temperature rolling and the martensitic transformation temperature is lower than $0 \mathrm{~K}[18]$. Therefore, martensite transformation is difficult to occur in this alloy. It is also well known that a low SFE $\left(<20 \mathrm{~mJ} \mathrm{~m}^{-2}\right)$ can favor the $\gamma \rightarrow \alpha^{\prime}$ phase transformation [19]. In this paper, the SFE of $\mathrm{Fe}-36 \% \mathrm{Ni}$ alloy is significantly decreased after cryogenic treatment. During CR, the low temperature would affect the dislocation cross-slip characteristics and cause severe distortions in crystal lattice, which promotes the strain-induced martensitic transformation [20]. Strain-induced martensite in Fe-36\%Ni alloy was also found by Shibata at 4 K [21]. 
However, due to the friction heat during rolling process, the SFE of will increase and the $\gamma \rightarrow \alpha^{\prime}$ phase transformation will be suppressed. This is why the volume fraction of strain induced $\alpha^{\prime}$ is only $15 \%$ in the present work.

The microstructure of samples after annealing treatment is shown in Fig. 4. As shown in Fig. 4a that a multimodal grain structure is formed after annealing at $823 \mathrm{~K}$ for $5 \mathrm{~min}$. It can be clearly seen that several fully recrystallized grains are embedded in the fine matrix. As known that the coarse grains can provide space to accommodate new dislocations and the fine matrix possess high density of defects during deformation, which can result in a high strength and high ductility mechanical properties $[8,9]$. As the increasing of annealing time, the recrystallized grains are evidently coarsened (Fig. 4b, 4c) and the volume fraction is increased. The cryorolled $\mathrm{Fe}-36 \% \mathrm{Ni}$ alloy is completely recrystallized after annealing at $823 \mathrm{~K}$ for $30 \mathrm{~min}$ (Fig. 4d) and the average grain size is $4.6 \mu \mathrm{m}$.

The microstructure of cryorolled $\mathrm{Fe}-36 \% \mathrm{Ni}$ alloy is mainly consisted of two typical regions: (1) highly deformed region which is composed of strain induced $\alpha^{\prime}$ or a large amount of dislocations. (2) low dislocation region. During annealing, the highly deformed regions are firstly recrystallized due to higher deformation stored energy. However, the recrystallization of low dislocation regions is more delayed. With the increasing of annealing time, the first recrystallized grains are gradually coarsened and the low dislocation regions are transformed to fine recrystallized grains. This causes a bimodal grain size distribution as shown in Fig. 5. The results indicate that nearly $62 \%$ of the grains are less than $3 \mu \mathrm{m}$ and there are a few large grains with 
grain size more than $10 \mu \mathrm{m}$. In addition, the average aspect ratio is 1.6 , revealing that the recrystallized grains are almost equiaxed.

Fig. 6 shows the engineering stress-strain curves for cryorolled and annealed samples. The cryorolled sample exhibits high ultimate strength (UTS) up to $1110 \mathrm{MPa}$, while the UTS of room temperature rolled one is only $810 \mathrm{MPa}$. This is mainly due to the formation of high density of dislocations and $\alpha^{\prime}$ during $\mathrm{CR}$, which indicates that CR can enhance the strength of Fe-36\%Ni alloy more effectively. CR has also been proved to be an effective strengthening approach in other metals. Zherebtsov et al. [22] found that the UTS of pure Ti after CR was $200 \mathrm{MPa}$ higher than room temperature one. The UTS of cryrolled pure Ni was enhanced to $1125 \mathrm{MPa}$, while the UTS of room temperature rolled sample was only $925 \mathrm{MPa}$ [23]. More dislocations can be preserved due to that low temperature can effectively inhibit the recovery and cross slip of dislocations.

After annealing at $823 \mathrm{~K}$ for $5 \mathrm{~min}$, the UTS of the tested alloy is decreased to $830 \mathrm{MPa}$ with the total elongation (EL) improved from 3 to $8 \%$. Compared to the room temperature rolled $\mathrm{Fe}-36 \% \mathrm{Ni}$ alloy, the mechanical properties of annealed specimen is obviously more excellent. Although, a multimodal grain structure is obtained (Fig. 4a), the combination of high strength and high ductility behavior is not achieved in $\mathrm{Fe}-36 \% \mathrm{Ni}$ alloy. A bimodal grain structure $\mathrm{Cu}$ with high strength and ductility was obtained by Wang et al. [8]. The main reason is that the fine matrix could provide high strength and the large grains provide high ductility. Similar results were discovered in pure Ti with multimodal grain structure after CR and annealing. 
The excellent mechanical properties were obtained due to the limited slip system in hexagonal close-packed (HCP) metals and twinning can be easily activated in the coarse grains [9]. In this work, the SFE of Fe-36\%Ni alloy is more than two times of pure $\mathrm{Cu}\left(55 \mathrm{~mJ} \mathrm{~m}^{-2}\right)$. The higher SFE results in a rapid recovery of dislocations and softening of deformed matrix during annealing. Besides, the large grains in $\mathrm{Fe}-36 \% \mathrm{Ni}$ alloy are absence of a higher work hardening rate due to twining cannot be activated as in pure $\mathrm{Cu}$ or $\mathrm{Ti}$. Therefore, $\mathrm{Fe}-36 \% \mathrm{Ni}$ alloy with high strength and high ductility behavior is difficult to obtain for the high SFE. The results of this work are similar to the findings investigated by Lee et al. [23]. It was reported that pure $\mathrm{Ni}$ with a multimodal structure was obtained by using CR and subsequent annealing, but the combination of high strength and high ductility was also not manufactured attribute to the high SFE $\left(214 \mathrm{~mJ} \mathrm{~m}^{-2}\right)$.

With the increasing of annealing time, it is easy to find that the enhancement of ductility is accompanied by the drastic decrease of the tensile strength. After annealing at $823 \mathrm{~K}$ for $30 \mathrm{~min}$, the UTS of the tested alloy is $550 \mathrm{MPa}$, total EL is $36 \%$. This good mechanical property is probably attributed to the bimodal microstructure.

\section{Conclusion}

In this paper, $\mathrm{Fe}-36 \% \mathrm{Ni}$ alloy was cryorolled with a $90 \%$ thickness reduction and subsequently annealed at $823 \mathrm{~K}$ for different times. The SFE of the Fe-36\%Ni alloy was significantly decreased after cryogenic treatment, which caused a great influence on microstructure evolution. By means of XRD and TEM, the phase transformation of 
$\gamma \rightarrow \alpha$ was confirmed to be induced during CR. The UTS of the cryorolled Fe-36\% Ni alloy was improved to $1110 \mathrm{MPa}$ due to high density defects formation during CR. A multimodal grain structure was produced in the tested alloy after annealing at $823 \mathrm{~K}$ for $5 \mathrm{~min}$, while the combination of high strength and high ductility behavior was not achieved in this work. The high SFE of the Fe-36\%Ni alloy resulted in a rapid recovery of dislocations during annealing, therefore, the ductility was increased with the significantly decrease of strength as the increase of annealing time. After annealing at $823 \mathrm{~K}$ for $30 \mathrm{~min}$, the cryorolled Fe-36\%Ni alloy was fully recrystallized and a bimodal grain size distribution was obtained. The bimodal microstructure was consisted of nearly $62 \%$ of the grains less than $3 \mu \mathrm{m}$ and a few large grains more than $10 \mu \mathrm{m}$. The average grain size was $4.6 \mu \mathrm{m}$, revealing that $\mathrm{CR}$ could be an effective method to grain refinement. The recrystallized sample exhibited a good mechanical property with a higher tensile strength of $550 \mathrm{MPa}$ and total EL of $36 \%$.

\section{Acknowledgments}

This work was supported by the National Science Foundation of China (51274062), Research Fund for the Central Universities (N130607002) and the Research Fund for the Doctoral Program of Higher Education of China (20130042110040).

\section{References}

[1] M. Shiga, Curr. Opin. Solid State Mater. Sci. 1 (1996) 340-348.

[2] S.P. Woong, M.S. Chun, M.S. Han, M.H. Kim, J.M. Lee, Mater. Sci. Eng. A 528 (2011) 
$5790-5803$.

[3] A. Gulyaev, E.L. Svistunova, Scr. Mater. 35 (1996) 501-504.

[4] R.R. Mulyukov, V.A. Kazantsev, K.Y. Mulyukov, A.M. Burkhanov, I.M. Safarov, I.K. Bitkulov, Rev. Adv. Sci. 11 (2006) 116-121.

[5] A. Vinogradov, S. Hashimoto, V.I. Kopylov, Mater. Sci. Eng. A 355 (2003) 277-285.

[6] T. Shanmugasundaram, B.S. Murty, V.S. Sarma, Scr. Mater. 54 (2006) 2013-2017.

[7] Y.H. Zhao, X.Z. Liao, S. Cheng, E. Ma, Y.T. Zhu, Adv. Mater. 18 (2006) 2280-2283.

[8] Y.M. Wang, M.W. Chen, F.H. Zhou, E. Ma, Nature. 419 (2002) 912-914.

[9] D.K. Yang, P.D. Hodgson, C.E. Wen, Scr. Mater. 63 (2010) 941-944.

[10] N. Rangaraju, T. Raghuram, B.V. Krishna, K.P. Rao, P. Venugopal, Mater. Sci. Eng. A 398 (2005) 246-251.

[11] P. Bhaskar, A. Dasgupta, V.S. Sarma, U.K. Mudali, S. Saroja, Mater. Sci. Eng. A 616 (2014) $71-77$.

[12] T. Konkova, S. Mironov, A. Korznikov, S.L. Semiatin, Acta Mater. 58 (2010) 5262-5273.

[13] V.S. Sarma, J. Wang, W.W. Jian, A. Kauffmann, H. Conrad, J. Freudenberger, Y.T. Zhu, Mater. Sci. Eng. A 527 (2010) 7624-7630.

[14] Q. Yang, J.L. Luo, Mater. Sci. Eng. A 288 (2000) 75-83.

[15] ASTM E8/E8M, 2009, Standard Test Methods for Tension Testing Metallic Materials, ASTM International, West Conshohocken, PA, 2009.

[16] B. Ma, C.S. Li, J.J. Zheng, Y.L. Song, Y.H. Han, Mater. Des. 92 (2016) 313-321.

[17] R.E. Schramm, R.P. Reed, Metall. Trans. A 7 (1976) 361-363.

[18] L.H. Zhu, Q.W. Huang, Mater. Lett. 57 (2003) 4070-4073. 
[19] K. Sato, M. Ichinose, Y. Hirotsu, Y. Inoue, ISIJ Int. 29 (1989) 868-877.

[20] Y.H. Zhao, Y.T. Zhu, X.Z. Liao, Z. Horita, T.G. Langdon, Appl. Phys. Lett. 89 (2006) 121906.

[21] K. Shibata, M. Kurita, K. Fujita, T. Fujita, International Conference on Martensitic Transformation, Nara, Japan. (1986) 25-30.

[22] S.V. Zherebtsov, G.S. Dyakonov, A.A. Salem, V.I. Sokolenko, G.A. Salishchev, S.L. Semiatin, Acta Mater. 61 (2013) 1167-1178.

[23] T.R. Lee, C.P. Chang, P.W. Kao, Mater. Sci. Eng. A 408 (2005) 131-135. 


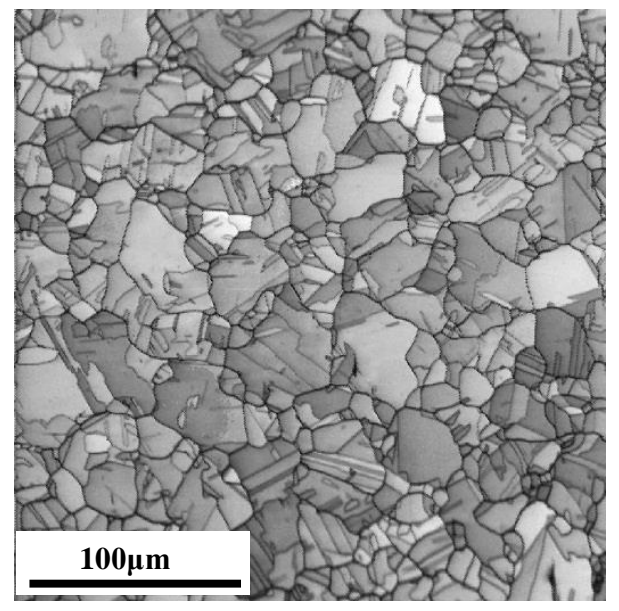

Fig. 1. Initial microstructure of the $\mathrm{Fe}-36 \% \mathrm{Ni}$ alloy after hot rolling. 


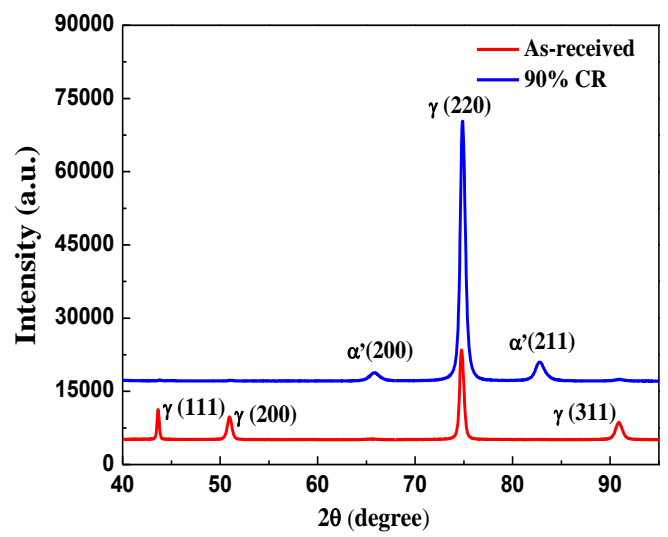

Fig. 2. X-ray diffraction patterns of the Fe-36\%Ni samples after hot rolling and $90 \% \mathrm{CR}$, showing the presence of $\gamma \rightarrow \alpha$ phase transformation. 


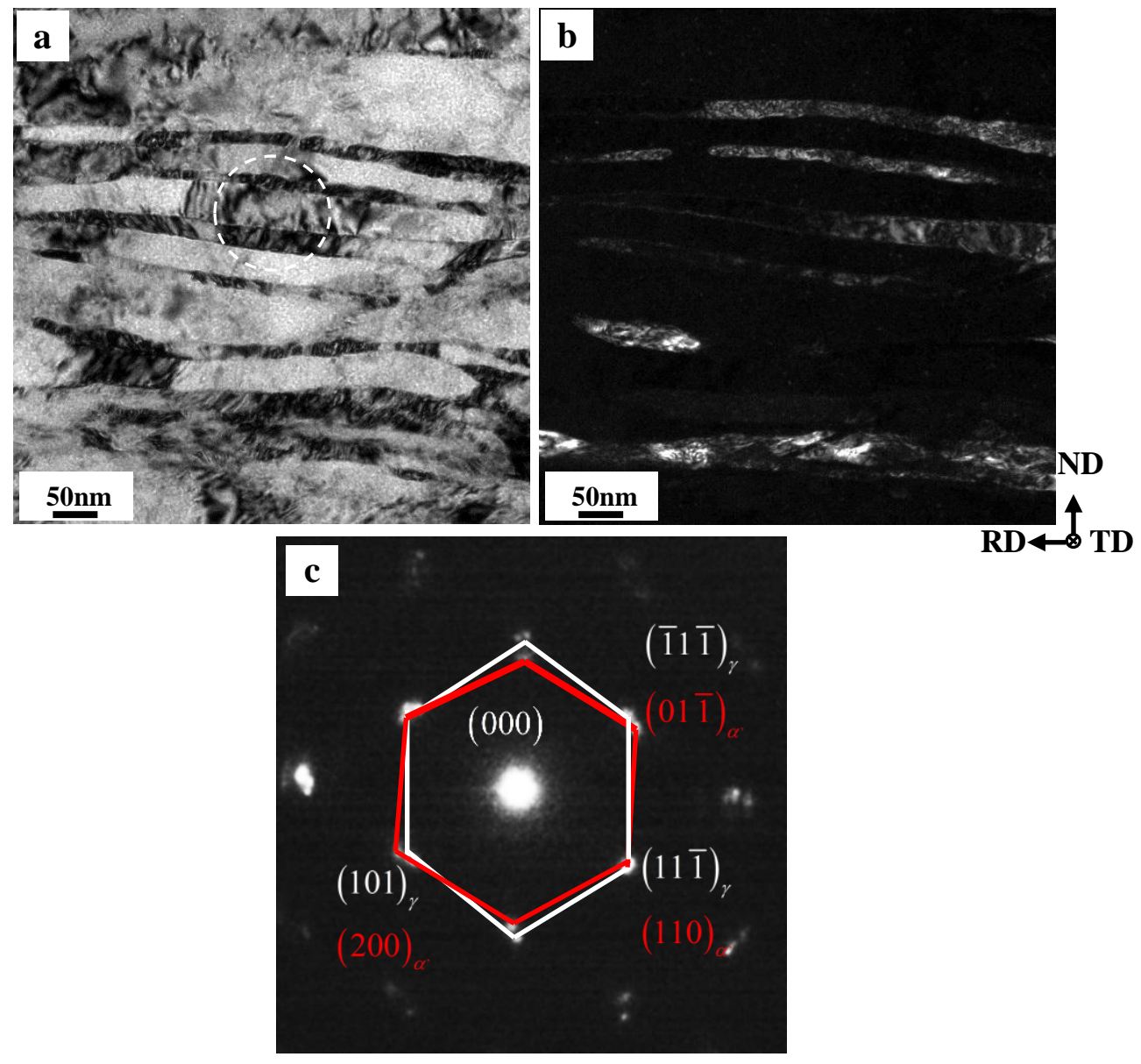

Fig. 3. TEM image of Fe-36\% Ni sample after $90 \% \mathrm{CR}$ (a), dark-field image of $\alpha^{\prime}$ (b), corresponding SAED pattern (c). 

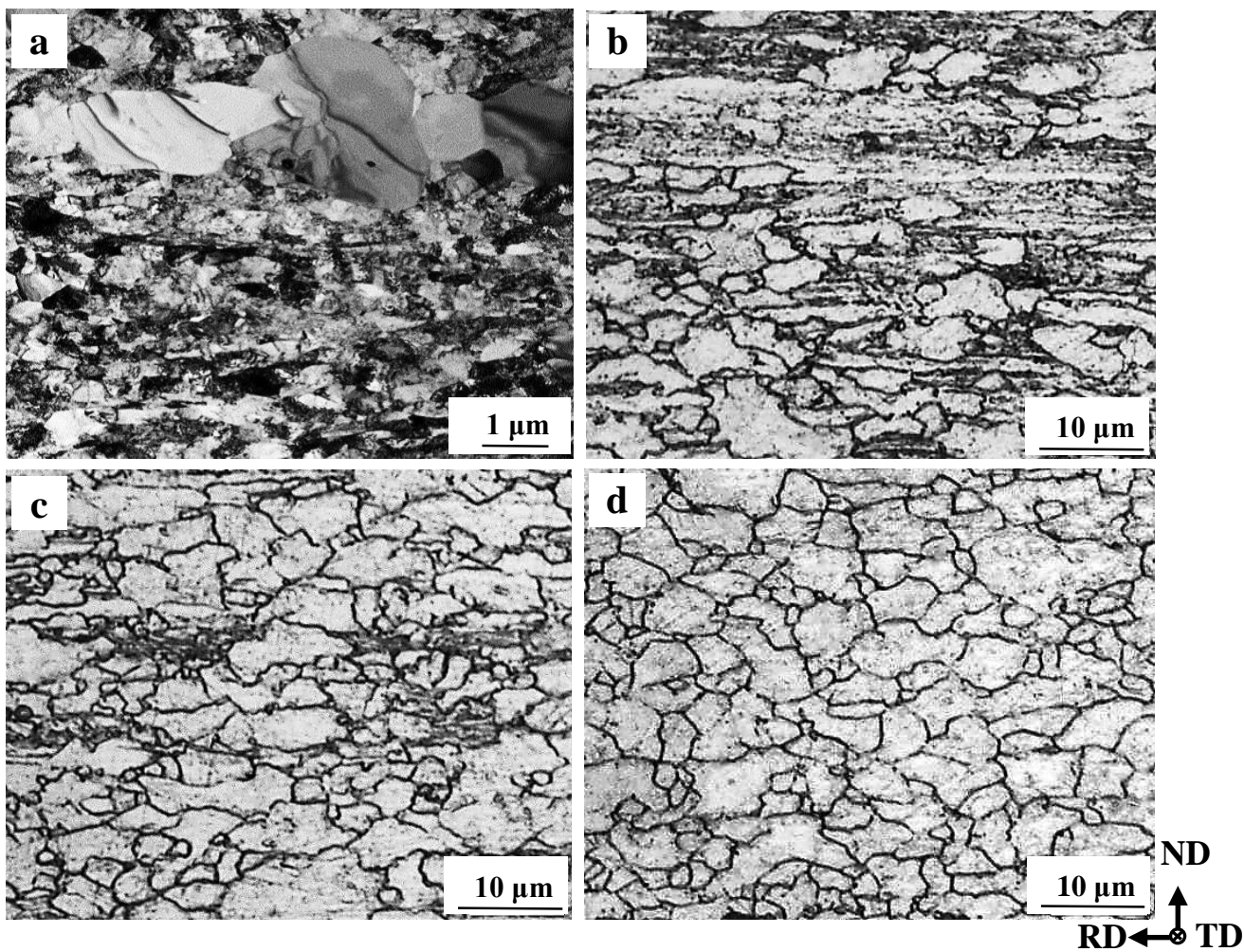

Fig. 4. Microstructure of cryorolled samples after annealing, TEM image showing the multimodal structure is formed after annealing for $5 \mathrm{~min}$ (a), optical image of samples after annealing at $823 \mathrm{~K}$ for (b)10 min (c) $15 \min (d) 30 \min$. 


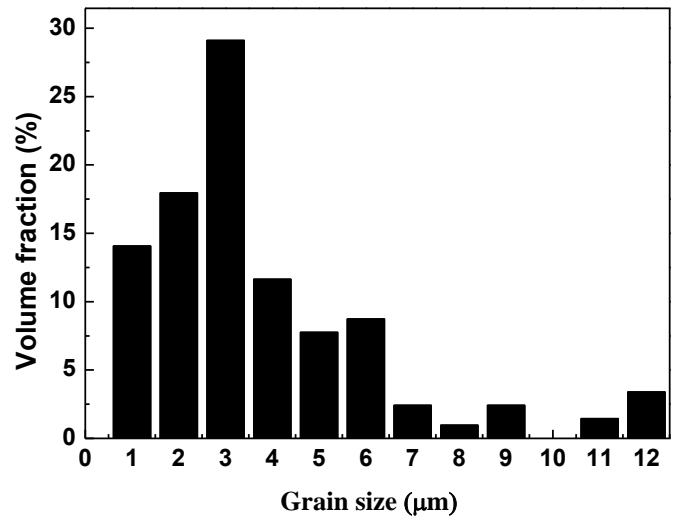

Fig. 5 The grain size distribution of cryorolled sample after annealing at $823 \mathrm{~K}$ for $30 \mathrm{~min}$. 


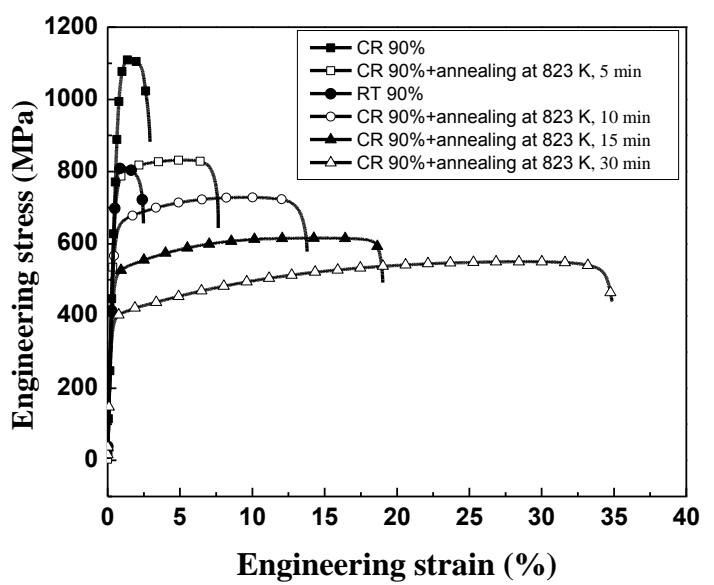

Fig. 6. Engineering stress - strain plot of rolled and annealed Fe-36\%Ni alloy. 
Table 1

X-ray reflections used in the quantitative determination of phase components

\begin{tabular}{cccc}
\hline Reflection & $\mathrm{d}(\AA)$ & Diffraction angle $(2 \theta)$ & R value \\
\hline$\{220\}_{\gamma}$ & 1.267 & 74.96 & 52 \\
$\{200\}_{\alpha}$ & 1.434 & 65.05 & 40 \\
$\{211\}_{\alpha}$ & 1.171 & 82.36 & 79 \\
\hline
\end{tabular}

